\title{
ÁGUAS RESIDUAIS INDUSTRIAIS: O CASO DE UM FRIGORÍFICO NO MUNICÍPIO DE PRESIDENTE PRUDENTE-SP ${ }^{1}$
}

\author{
Edilene Mayumi Murashita Takenaka² \\ Bruna Antico Piva da Silva ${ }^{3}$ \\ Simone Rodrigues Duarte Rocha ${ }^{4}$
}

\begin{abstract}
Resumo: As águas residuais industriais geradas e a sua inadequada disposição final constituem grandes focos de poluição ambiental. Aos empresários, resta a conscientização acerca desse problema e o oferecimento de alternativas para um meio ambiente livre de poluição que proporcione à empresa uma imagem positiva frente à questão ambiental. Como objetivo geral, a presente pesquisa buscou verificar 0 gerenciamento de águas residuais industriais geradas a partir da atividade de uma empresa do ramo de abate de gado bovino estabelecida no município de Presidente Prudente-SP. Para tanto, o presente trabalho considerou a necessidade dos pesquisadores envolvidos em buscar uma compreensão particular do tema estudado fazendo uso da abordagem qualitativa e tendo como materiais, referencial bibliográfico, estudo de caso e aplicação de questionários e entrevistas realizadas junto à empresa analisada. Concluímos que, dentro dos preceitos cabíveis, a empresa em questão apresenta um adequado gerenciamento de suas águas residuais.
\end{abstract}

Palavras-chave: Águas residuais. Meio Ambiente. Gerenciamento. Recurso hídrico. Bacia hidrográfica.

\section{INTRODUÇÃO}

\footnotetext{
${ }^{1}$ Este trabalho faz parte das discussões que envolveram a elaboração de um trabalho de conclusão do curso de Administração da Universidade do Oeste Paulista - Unoeste.

${ }^{2}$ Doutora em Geografia - Unesp, Docente do Mestrado em Meio Ambiente e Desenvolvimento Regional da Unoeste (edilene@unoeste.br)

3 Bacharel em Administração-Unoeste (brunapiv@hotmail.com)

${ }^{4}$ Bacharel em Administração-Unoeste (materiaisconstrucaobetel@hotmail.com)
} 
O crescimento da população brasileira associada ao aumento de sua expectativa de vida trouxe, somada às melhores condições de acesso à saúde e educação propiciada pelas cidades, sua concentração nos centros urbanos.

Tal processo de concentração urbana tem se mostrado acentuado nas últimas décadas e, concomitante ao aumento do poder aquisitivo das famílias brasileiras ocasionado por diversas políticas de distribuição e redistribuição de renda, colocadas em pauta no início do século XXI, acabou por alavancar o uso dos recursos energéticos e hídricos ao fornecer condições de ampliação do consumo.

Assim, o aumento da população brasileira e sua concentração urbana somada às facilidades de consumo ampliou a demanda por bens duráveis ou não duráveis fortalecendo a atividade produtiva para satisfazer a essas necessidades de consumo. Com isso, amplia-se o descarte de resíduos sólidos e líquidos contribuindo efetivamente para agravar a poluição ambiental uma vez que toda atividade humana que envolva produção e consumo gera resíduos. (TAKENAKA, 2008)

A NBR 10004 (ABNT, 2004) define como resíduos sólidos "os resíduos nos estados sólido e semi-sólido, que resultam das atividades da comunidade de origem: industrial, doméstica, hospitalar, comercial, agrícola, de serviços e de varrição". Tais resíduos são gerados sob a forma de plásticos, metais, papéis, vidros, pneus, entulhos, lixo eletrônico, substâncias químicas e alimentos.

O que fazer com esses resíduos gerados para que sua disposição final cause o mínimo de impactos negativos ao meio ambiente é um desafio enfrentado por grande parte dos municípios brasileiros, pois tanto no processo produtivo quanto após a utilização de mercadorias e serviços, os resíduos costumam ser coletados e transportados sem qualquer tipo de seleção ou triagem e, em seguida, dispostos em locais inadequados, causando prejuízos ao meio ambiente e à coletividade.

Todos os estágios das atividades humanas geram resíduos e as principais preocupações estão voltadas para as repercussões que podem ter sobre a saúde humana e sobre o meio ambiente em que é depositado (solo, água, ar e paisagens).

Assim, observamos que esse processo de crescimento populacional nos centros urbanos e a ampliação na demanda por maiores quantidades de bens e mercadorias trouxe a necessidade de um desenvolvimento industrial que, ao proporcionar ao ser humano melhor qualidade de vida sobrevivência e conforto contribui para o aumento da 
utilização de recursos produtivos renováveis ou não renováveis e na ampliação da geração de resíduos industriais.

De acordo com a NBR 9800/1987, efluente líquido industrial é o despejo líquido proveniente do estabelecimento industrial, compreendendo emanações de processo industrial, águas de refrigeração poluídas, águas pluviais poluídas e esgoto doméstico.

Os resíduos perigosos produzidos pelo setor industrial gerados em fábricas, usinas, manufaturas em geral, cujos materiais variam em função do tipo de indústria e do processo de produção empregado são particularmente preocupantes quando incorretamente gerenciados, pois se transformam em grave ameaça poluidora para 0 meio ambiente ao gerar águas residuárias ${ }^{5}$, emissões atmosféricas e resíduos sólidos podendo trazer impactos negativos aos recursos hídricos, à atmosfera e o ambiente solo.

Segundo Oliveira e Lange (2005, p.2):

A geração de resíduos sólidos na atividade industrial não se restringe às etapas do processo produtivo, nas quais ocorrem descartes de subprodutos, que não possuem valor econômico. Nessas atividades, os sistemas de tratamento de águas residuárias e emissões atmosféricas são importantes geradores de resíduos sólidos.(...)

(...) Os problemas ambientais associados à geração e destinação de resíduos sólidos industrias podem provocar impactos negativos sobre a biosfera, trazendo conseqüências para os recursos hídricos, a atmosfera e o ambiente solo. Os impactos da disposição inadequada dos resíduos sólidos estão relacionados principalmente com contaminação das águas subterrâneas e solo, podendo causar desequilíbrio dos ecossistemas e afetar a saúde humana.

A preocupação com um adequado gerenciamento de resíduos industriais sejam eles sólidos ou líquidos demonstra que a empresa possui conscientização ambiental e respeito para com a sociedade e deve privilegiar ações que contribuam para a redução dos impactos ambientais por ela gerados.

O presente estudo buscou abordar o tema gestão de efluentes líquidos industriais a partir de um estudo de caso em que foi analisada a forma adotada de gerenciamento de águas residuais geradas, derivados da atividade de uma empresa do ramo de abate ${ }^{6}$ de gado bovino estabelecida no município de Presidente Prudente-SP.

\footnotetext{
${ }^{5}$ Águas residuárias, águas residuais, resíduos líquidos e efluentes líquidos são as águas descartadas como resultado de processos diversos como a atividade industrial.

${ }^{6}$ Abate: matadouro ou frigorífico; é o abatimento de origem animal, sendo que este é normalmente localizado em instalaçoes originais.
} 
Para o desenvolvimento da pesquisa foi adotada a abordagem qualitativa e teve como materiais, referencial bibliográfico, estudo de caso, elaboração e aplicação do questionário e entrevistas junto a funcionários e proprietários da empresa analisada.

Esse tipo de estudo envolveu um número menor de entrevistados possibilitando uma maior abertura para eles se expressarem em relação ao assunto sem preocupação com estatísticas. Utilizamos a pesquisa de campo com estudo de caso e entrevistas para que se conseguisse coletar dados e investigar os fenômenos diretamente onde eles ocorrem ao restringir o público-alvo a apenas uma unidade empresarial.

A ideia clara que se obteve é que há a necessidade de adotar métodos que minimizem o impacto agressor ao meio ambiente, provindas dos efeitos negativos da maioria das empresas. Tais métodos devem ser continuamente praticados, para que as futuras gerações também possam desfrutar da natureza, e que estes saibam que ainda existem organizações empresariais que buscam melhorias neste fator e que se atualizam neste seguimento.

\section{2 ÁGUAS RESIDUÁRIAS E CARACTERIZAÇÃO DA EMPRESA ANALISADA}

Situada no município de Presidente Prudente, região oeste do Estado de São Paulo, a empresa analisada atua no setor de abate de gado bovino e pode, também, ser identificada como frigorífico. Possui uma área de $270.000 \mathrm{~m}^{2}$ com capacidade para abater cerca de 1.000 cabeças/dia de bovino.

O município de Presidente Prudente-SP localiza-se sobre um espigão divisor de águas das bacias do rio do Peixe (Norte), e Paranapanema (Sul), tendo a bacia do rio Santo Anastácio, que deságua no rio Paraná (Sul-sudoeste). A empresa responsável pelos serviços de saneamento básico no município é a SABESP ${ }^{7}$ que utiliza como fonte de captação de água na superfície: o Rio do Peixe, o Balneário da Amizade e o Rio Santo Anastácio.

Segundo Teodoro e Nunes (2010, p.6), o município de Presidente Prudente-SP:

Caracteriza-se por possui um sistema hidrográfico constituído por pequenos cursos d'água, formadores dos córregos do Cedro e do Limoeiro, ambos afluentes do rio Santo Anastácio, e do Gramado e da

\footnotetext{
${ }^{7}$ Sabesp - empresa de economia mista responsável pelos serviços de saneamento básico que consistem na captação, tratamento e distribuição de água, coleta e tratamento de esgotos no município de Presidente Prudente-SP.
} 
Cascata, formadores do rio Mandaguari, o qual, por sua vez, é afluente do rio do Peixe, localizado no setor Leste-nordeste da cidade. Os cursos fluviais mais importantes são o córrego do Veado, que possui o da Colônia Mineira como afluente, os quais formam a micro bacia do Limoeiro, e do Cedro, que possui o do Botafogo como afluente. Uma sucessão de espigões em colunas sedimentares suavemente onduladas, com altitudes entre 400 e $480 \mathrm{~m}$,com vertentes essencialmente convexo-côncavas, caracterizam o relevo destas microbacias.

O Rio do Peixe é responsável por $70 \%$ do abastecimento de água no município e a captação do Rio Santo Anastácio garante os 30\% restantes sendo que, em casos emergenciais, para não comprometer o fornecimento de água para os moradores, a captação do Balneário da Amizade é ativada ${ }^{8}$.

A atividade produtiva da empresa pesquisada é responsável pela geração de efluentes líquidos que são lançadas diariamente no Córrego do Veado.

O Córrego do Veado, com extensão de $3.417 \mathrm{~km}$, é afluente do Córrego do Limoeiro que, por sua vez, desemboca no Rio Santo Anastácio e encontra-se dividido em duas partes: uma canalizada e outra não.

A porção canalizada do córrego encontra-se em uma área totalmente urbanizada, no Parque do Povo. Na porção não canalizada, ele recebe efluentes de várias indústrias, incluindo da empresa pesquisada no presente trabalho.

Um fato interessante é a localização do empreendimento muito próxima à bairros urbanizados apesar da Norma Técnica para Estabelecimentos de Abate de Bovídeos, Suídeos, Caprídeos e Ovinos enfatizar em seu artigo $2^{\circ}$ que o estabelecimento de abate deve estar em área rural, afastado no mínimo 15 metros de vias públicas.

Afirmam os responsáveis pela empresa que, no início de suas atividades, sua localização era considerada periférica e longe de bairros habitados. Entretanto, o frigorífico em questão buscou adaptar suas atividades de acordo com as leis de saneamento vigentes uma vez que, com o passar dos anos, a malha urbana cresceu ao redor da mesma.

Em geral, as empresas que atuam no abate de gado bovino demonstram uma grande preocupação ambiental, seja devido às punições estipuladas por lei, à sua

\footnotetext{
${ }^{8}$ Sabesp. Disponível em $<$ http://www.sabesp.com.br/CalandraWeb/CalandraRedirect/?temp=4\&proj=AgenciaNoticias\&pub=T\&db=\&docid=CA699 C8ACE14E634832576CE005009E2>. Acesso em 05/07/2013.
} 
imagem perante uma sociedade mais consciente, à preocupação genuína com o meio ambiente ou mesmo à soma de todos esses fatores.

O importante a observar é que essas empresas preocupam-se com as práticas a serem adotadas em relação ao tratamento dos efluentes líquidos gerados nestas atividades, uma vez que, devido à presença de subprodutos e resíduos dessa atividade (sangue, pedaços de carne, gorduras, entranhas e vísceras) necessitam adotar formas de processamentos e destinações adequadas em atendimento às leis e normas vigentes, sanitárias e ambientais.

\section{RESULTADOS DA PESQUISA}

Quando questionados sobre a destinação dos efluentes líquidos e dos resíduos sólidos originários de sua atividade produtiva, os entrevistados afirmaram que a empresa conta com um protocolo interno obedecendo normativas do Serviço de Inspeção Federal (SIF) e da Análise de Perigos e Pontos Críticos de Controle (APPCC) que consiste na reutilização da quantidade de água que é utilizada diariamente para a limpeza da carne e, com o processo de reutilização dos resíduos sólidos que também são gerados internamente. Antes de ser devolvida ao meio ambiente, a água utilizada passa por processos internos de limpeza e tratamentos químicos.

Em relação aos materiais passíveis de reciclagem como papéis, vidros, catálogos de produtos entre outros, os mesmos são separados e disponibilizados para a coleta seletiva.

Como na empresa existe o setor destinado aos animais, há resíduos hospitalares e estes, são contaminados, mesmo sendo em proporções pequenas. Tais resíduos são acondicionados em sacos plásticos apropriados e encaminhados para coleta específica de materiais que representam riscos de contaminação.

Sobre os despojos dos setores de desossa, abate e miúdos, afirmaram que esses resíduos são encaminhados ao setor de farinha de carne e ossos, onde é produzida a farinha e extração do sebo bovino. O sangue proveniente do abate é processado e transformado em farinha de sangue. 
Os entrevistados enfatizaram que apenas os resíduos líquidos são encaminhados às lagoas de tratamento e que a empresa preocupa-se em treinar a mão-de-obra sobre boas práticas de fabricação com treinamentos oferecidos a seus funcionários a cada seis meses.

A fim de confirmar a prática do protocolo interno mencionado, as pesquisadoras realizaram uma pesquisa de campo para acompanhar as ações desempenhadas pela empresa pesquisada e verificou os seguintes procedimentos:

a) Após a utilização da água para limpeza no processo de abate, a mesma é filtrada para a separação dos resíduos em sólidos e líquidos: os resíduos sólidos são provenientes da graxaria e transformados em farinha para adubação; os resíduos líquidos são aqueles destinados à estação de tratamento de efluentes localizada na própria empresa;

b) Com os resíduos separados em sólidos e líquidos, o processo de limpeza química dos resíduos líquidos tem início ao passar por duas linhas: a linha verde resultado da lavagem das tripas e a linha vermelha que contém o sangue dos animais abatidos que será transformado em farinha;

c) Na sequencia, os resíduos líquidos passam por um processo de decantação em que é aplicada uma bactéria que consome a matéria orgânica ainda existente por sete dias em um tanque com capacidade de 7.000 .000 milhões de litros;

d) Após os sete dias os resíduos líquidos passam para outro tanque com capacidade de 9.000 .000 milhões de litros e, é nele que começa o tratamento biológico e depois químico para aumentar a porcentagem de pureza da água (tais procedimentos são realizados desde 1998);

e) A água residuária passa por um processo de flotação. Nesse processo, as microbolhas produzidas na câmara de flotação se prendem às partículas sólidas e óleos formando aglomerados carregados (espuma) para a superfície. A espuma produzida na superfície é então retirada;

f) A água residuária está pronta para ser devolvida ao meio ambiente como efluente do Córrego do Veado.

$\mathrm{Na}$ foto 1, podemos observar três amostras (da esquerda para a direita): o recipiente com a água mais escura tirada diretamente da linha verde sem nenhum tipo de 
tratamento; o recipiente com a água mais clara retirada após o processo de decantação e o recipiente com a água mais cristalina retirada após o término do tratamento realizado pela empresa pesquisada e pronta para ser devolvida ao meio ambiente.

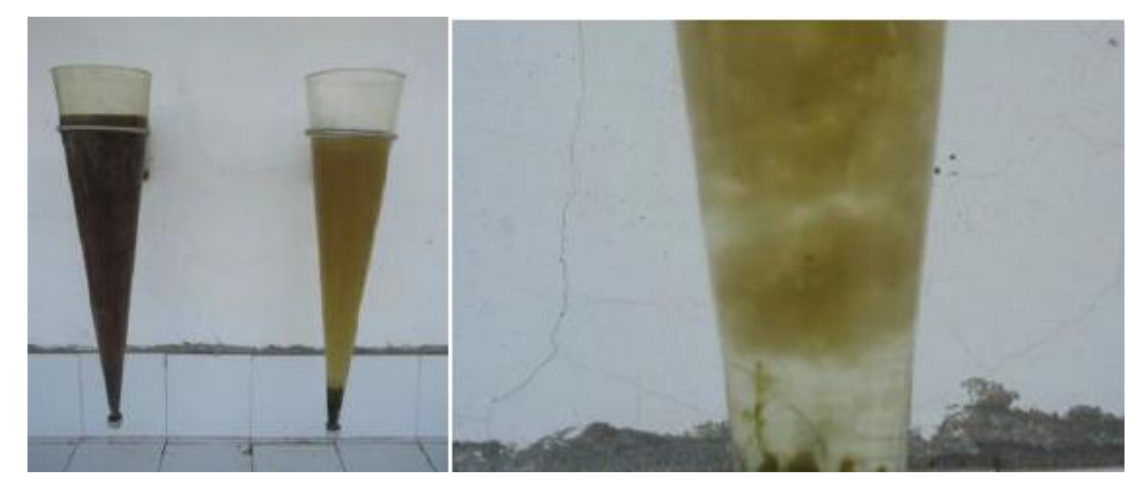

Foto 1 - Amostras da água residuária Autoria: SILVA e ROCHA (25/10/2012)

De acordo com o funcionário responsável pelo setor, após a conclusão das etapas de tratamento realizado pela empresa, a água residuária despejada no Córrego do Veado pode ser classificada como de classe 2 .

Segundo a RESOLUÇÃO CONAMA No 357, DE 17 DE MARÇO DE 2005, a água classificada como de classe 2 pode ser definida da seguinte forma:

Classe 2: águas que podem ser destinadas: a) ao abastecimento para consumo humano, após tratamento convencional; b) à proteção das comunidades aquáticas; c) à recreação de contato primário, tais como natação, esqui aquático e mergulho, conforme Resolução CONAMA no 274, de 2000; d) à irrigação de hortaliças, plantas frutíferas e de parques, jardins, campos de esporte e lazer, com os quais o público possa vir a ter contato direto; e e) à aquicultura e à atividade de pesca. (BRASIL, 2005, p.4)

Portanto, os representantes da empresa pesquisada acreditam adotar medidas adequadas no caso do tratamento da água residual que produzem.

\section{CONCLUSÃO}




\section{Then \\ Fórum Ambiental \\ da Alta Paulista}
ISSN 1980-0827
Volume 9, Número 11, 2013
Saúde, Saneamento e
Meio Ambiente

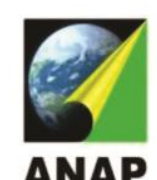

ANAP

As atividades humanas, sejam produtivas ou de consumo, geram resíduos e os mesmos dispostos na natureza sem adequado tratamento e disposição final acarretam graves danos ambientais.

A presente pesquisa teve como objetivo geral verificar o gerenciamento de águas residuais industriais geradas a partir da atividade de uma empresa do ramo de abate de gado bovino estabelecida no município de Presidente Prudente, região oeste do Estado de São Paulo.

A partir do trabalho desenvolvido foi possível observar que, a empresa pesquisada, segue um protocolo interno obedecendo as normativas do Serviço de Inspeção Federal (SIF) e da Análise de Perigos e Pontos Críticos de Controle (APPCC).

A maior parte do resíduo produzido pelo frigorífico em questão é apresentada sob a forma de matéria química orgânica biodegradável em que a aplicação de um tratamento físico, sequenciado por um tratamento biológico e finalizado pela aplicação de tratamento físico-químico, tornou-se o mais adequado para a obtenção de um efluente final, classe 2 , atendendo à RESOLUÇÃO CONAMA No 357, DE 17 DE MARÇO DE 2005.

Dessa forma, a empresa pesquisada demonstra adotar práticas adequadas de gerenciamento de sua água residuária, que atende às normatizações atuais e permite a continuidade de sua atividade industrial.

\section{REFERÊNCIAS}

ABNT Associação Brasileira de Normas Técnicas, 2004. Resíduos Sólidos - Classificação - NBR10.004. Rio de Janeiro: ABNT.

BRASIL. Ministério do Meio Ambiente, Conselho Nacional de Meio Ambiente, CONAMA. Resolução CONAMA no 357/2005, de 17 de março de 2005. Estabelece parâmetros para lançamento de efluentes em corpos d'água.Disponível em: < http://portal.saude.gov.br/portal/arquivos/pdf/resolucao conama357.pdf> Acessado em: 10/07/2013.

OLIVEIRA, G. A. G. e LANGE, L. C. Gerenciamento dos resíduos sólidos industriais na área mineira da bacia hidrográfica do médio São Francisco. In 23ํ Congresso Brasileiro de Engenharia Sanitária e Ambiental. 2005. Disponível em http://www.bvsde.paho.org/bvsacd/abes23/III-195.pdf. Acesso em 10/07/2013. 
TAKENAKA, E. M. M. Políticas públicas de gerenciamento integrado de resíduos sólidos urbanos no município de Presidente Prudente-SP, Presidente Prudente: FCT, UNESP, 2008, f. Tese (Doutorado) - Faculdade de Ciências e Tecnologia, Universidade Estadual Paulista, 2008.

TEODORO, P. H. M. e NUNES, J. O. R. Os alagamentos em Presidente Prudente-SP: um trabalho interdisciplinar embasado no mapeamento geomorfológico. Revista Formação, n.17, 2010, volume 2 - p. 81-102. Disponível em $<$ http://revista.fct.unesp.br/index.php/formacao/article/viewFile/456/490>. Acesso em $10 / 07 / 2013$. 